\title{
GradUATE ATTRIbUTE ASSESSMENT IN SOFTWARE ENGINEERING Program at University of OtTaWA - Continual IMPROVEMENT PROCESS
}

\author{
Aneta George, Timothy Lethbridge, Liam Peyton \\ University of Ottawa, 800 King Edward, Ottawa, ON, Canada K1N 6N5 \\ atrai062@uottawa.ca, tcl@eecs.uottawa.ca, lpeyton@uottawa.ca
}

\begin{abstract}
Management, measurement, and visualization of graduate attributes in a program can be complex and challenging. At the University of Ottawa, we have developed a Graduate Attribute Information Analysis system (GAIA) to support performance management of graduate attributes. It simplifies data collection and improves visualization of results with historical trend analysis at both the course level and the program level. Graduate attribute measurements are defined in a tool that can flexibly integrate internal indicators (such as tests, assignments, exam questions) or external indicators (such as surveys or feedback forms). We have mapped the assessment results with a four-scale rubric that allows the use of weighted grading when dominant and secondary components apply. And we support measurement-specific range boundaries to better match the expected level of knowledge students must achieve.
\end{abstract}

Keywords: CEAB, Accreditation, Assessment Outcomes, Performance Indicator, Graduate Attribute.

\section{INTRODUCTION}

\subsection{Motivation}

As part of the accreditation process in Canada, undergraduate engineering programs are obligated to demonstrate that their programs effectively train students in the twelve CEAB Graduate Attributes (GA) [1]. They are obligated to establish a measurement process of these 12 GA throughout the program, and use the data for continuous improvement. Establishing a proper system for data collection, reporting, analyzing and tracking historic data trends to inform future program improvement is essential for accreditation. In this paper, we evaluate the Graduate Attributes Information Analysis system (GAIA) developed at the University of Ottawa for data collection and analysis and outline the graduate attribute evaluation process that has been implemented using the tool.

\subsection{Literature Review}

To develop and establish an efficient procedure for assessing GA we first explored related publications from different Canadian universities. Harris et al give detailed explanations on the process of merging CEAB GA and Undergraduate Degree-Level Expectations at Carleton University [2]. In the process of merging, they have identified the need of adding a missing graduate attribute, Attribute 13 - Limits of Knowledge. An interesting way of defining sub-attributes and relating them with their respective indicators, measures and rubrics was done at the University of Alberta [3]. A similar model of program mapping is shown at the University of British Columbia [4]. It uses existing course evaluation tools whenever possible in the data collection process. They also show how analysis and interpretation of data was implemented to identify strengths and weaknesses within the programs. The University of Calgary divides the GA into SubCategories and breaks down each sub-category into learning objectives [5].

In terms of finding suitable software support for outcomes-based assessment, we look at tools developed by vendors and available on the market, as well as software solutions created by different engineering schools. In 2012 in a joint paper from Queen's University, University of Calgary, University of Toronto, Concordia University, University of British Columbia, University of Manitoba and Dalhousie University compared their institutional approaches to CEAB GA requirements. Concordia's AAS LMS has been identified as most notable for its capability to collect data and rubrics and its ability to allow data sharing between instructors [6].

Kaupp, Frank and Watts [7] evaluate different software tools supporting outcomes-based assessment. Kaupp and Frank [8] follow up on the research and classify them into five categories - Learning Management Systems (LMS), Learning Content Management Systems (L/CMS), Assessment Platforms (AP), Analytics Systems (AS) and Curriculum Mapping Tools (CMT) according to the varieties of roles each tool serves. Kaupp and Frank 
[9] conclude that different software tools may be used to assist in different aspects of the graduate assessment process. They set up an evaluation criteria to be used when adopting a software tool. The authors stress on the importance of selecting a tool based on its functionality and compatibility with local needs rather than its popularity. [9].

Several universities have created their own software information systems. Saunders and Mydlarski from McGill University introduce an interesting approach in the search for a learning management system adaptable to the needs of their Faculty of Engineering [10]. They discuss the evolution of instructors' own methods and tools to faculty-wide in-house tools to using the commercially purchased learning management software. The authors identify the process of actual measuring GA performance as the most difficult step in meeting the CEAB graduate attributes and continual program improvement criteria.

American universities are also using their own assessment tools rather than adopting an off the shelf system [11]. A comparison of the features in two off-theshelf systems, Compass and Outcomes Database, and the ABET Course Assessment Tool (ACAT), created at the University of Nevada, show $100 \%$ compatibility for ACAT, $33.3 \%$ for Compass and $66.7 \%$ for Outcomes Database.

We also revised publications outlining the experience of ABET (EC 2000), Australian Engineers and UK Engineering Council in their process of accreditation. Through exploring development of GA in Australian universities, Radloff, De La Harpe, Dalton, Thomas and Lawson have identified that the academic staff finds that assessing GA has proven challenging for the last decade [12]. They see the solution as deeper engagement of the staff into shared understanding on how to teach and assess GA. These rather political reasons for academics' resistance become a subject of Chanock's article on developing criteria to assess GA [13]. Chanock proposes a step down from the mandatory adoption of GA and instead empowers instructors to identify the GA they see most integrated into their subject.

At the University of Ottawa, we have implemented the same approach. Our GAIA tool gives freedom to academic staff involved in assessing particular KPI to identify and use agreed upon assessments they find most appropriate for the purpose of that GA evaluation.

\subsection{The Problem}

Difficulties in incorporating learning outcomes into GA have been identified as one of the reasons for the gap between what is valued and what is taught [14]. Thus, the task of reducing complex GA to Key Performance Indicators (KPI) and defining their respective learning outcomes becomes the first challenge. Finding a way to use (when possible) and/or modify (when needed) assessment tools and rubrics already in place is second. The last most challenging task is to incorporate GAs, KPIs, assessment tools, measurement criteria, course information sheets, data collection and analysis into one information system that generates achievement reports and informs program improvement. In addition, the assessment system needs to be user-friendly and timeefficient. It serves the purpose of (i) measuring GA performance and informing continual program improvement, and (ii) minimizing the overload and tension accompanying any data collection and analysis process.

\subsection{Solutions Considered}

In early 1990's the graduate attributes in Australia were referred to as Personal Transferable Skills [13]. One of the first formal definitions of the term Graduate Attributes describes them as "qualities, skills and understandings a university community agrees its students should develop during their time with the institution"[15]. In 2006, Paul Hager and Susan Holland define graduate attributes as "collection of various qualities and capacities distinguished from the discipline-specific knowledge and associated technical skills"[16]. In 2006, Simon Barrie gives the most popular definition of GA as "skills, knowledge and abilities of university graduates, beyond disciplinary content knowledge, which are applicable to a range of contexts"[17].

At the University of Ottawa, we have adapted Barrie's description, and we have matched each GA to discrete learning outcomes that can be measured. Course instructors have selected an appropriate assessment tool to measure each specific learning outcome for their course. Collecting data was done at a course level through a spreadsheet filled in by the instructor. Then data from those spreadsheets was imported into another Excel summary sheet for analysis and reporting across all courses in a program. This process served well at the initial stage of accreditation, but over time has proven to be highly inefficient. Several tools on the market were considered, but the compatibility of those tools to the GA analysis and development process we already have in place is problematic. Thus, we looked at ways of improving our in-place resources and evolving them into an information system, Graduate Attributes Information Analysis system (GAIA).

\subsection{Selected Methodologies}

The process of GA data collection is course-level based. The Course Data Entry Form automatically generates reports and graphs showing engineering graduate assessment based on data entered by instructors. 
Assessment tool used in evaluating student achievement toward specific LO is selected by academic staff. In cases when course instruction is shared by several instructors, assessment tool choice is a collective decision. Data entered into the system is being processed, analyzed and reported at program level. The tool in its current stage is already online and we are looking to improve issues related to security, data access and sharing.

\subsection{Significance of the results obtained}

Analysis and reports are being generated by GAIA through Course Data Entry Form and Program Report Form. Thus, the tool informs program improvement at both levels. It provides better visualization of the results by presenting them in graph and table form. Data entry is executed through Excel spreadsheets, which minimizes the need for user training. Visual Basic support allows for easy access to dynamic interactive charts. The software engineering program has been using it for a year now, and we are in the process of rolling it out to other engineering programs at the University of Ottawa.

\section{UNIVERSITY OF OTTAWA GRADUATE ATTRIBUTES INFORMATION SYSTEM}

\subsection{System Structure}

CEAB measures program performance according continual improvement as measured against graduate attributes. This requires assessing program performance levels against program expectations for twelve graduate attributes and establishing a procedure for program review leading to actions for program improvement. Figure 1 shows the continual program evaluation and improvement cycle we have established at University of Ottawa. The shaded ovals indicate the parts of the cycle that are directly supported by GAIA.

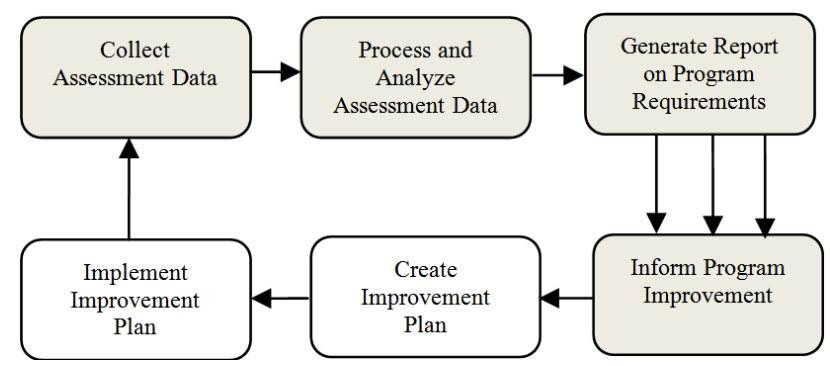

Fig. 1. Program Evaluation and Improvement Cycle.

GAIA has two components - a Course Data Entry Form (CDEF) per course and Program Report Form (PRF) per program. Each form is implemented as a macro-enabled Excel Spreadsheet that is delivered and collected through a web interface. At this stage, we have three programs assessing GA development through GAIA.

Each CDEF feeds data to a PRF that generates GA reports at the program level. Figure 2 shows the relation between GAIA components. At this stage, the reports are built on data from last four years (2012-2015). Currently GAIA is set up to accumulate data analysis and reports until year 2020 when our next accreditation will take place. Instructors enter assessment data by the end of each semester. A system administrator oversees if the process is completed on time and initiates emails to academic staff if needed.

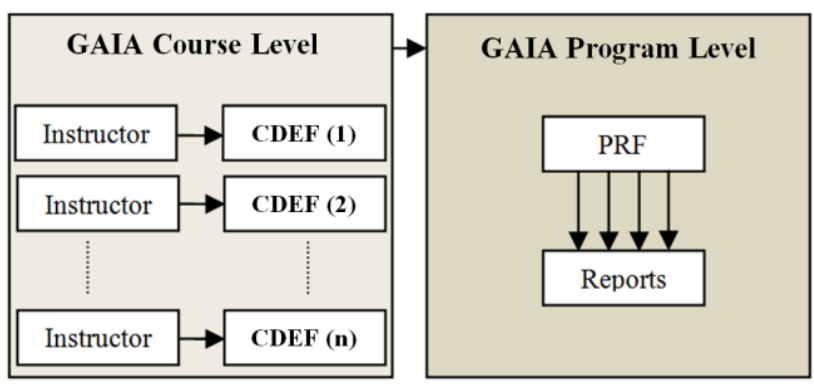

Fig. 2. GAIA Components.

\section{2. Course Data Entry Form}

The CDEF accommodates qualitative and quantitative data. Instructors enter data manually or copy-and-paste from the university grades management system (blackboard) when the measurement tool is based on course data. However, student surveys, employer surveys (for COOP), and other qualitative measures can be used as well. There is a column for each learning outcome measured relevant to a GA. Each cell contains a student score. Entering student identifiers is optional since we are simply interested in aggregating the results to support analysis per cohort, not per student. Instructors can adjust how they measure the learning outcome, but not the list of learning outcomes and graduate attributes assessed. If a change is required, it can be done by the system administrator, upon approval by the Program Curriculum Committee. The CDEF provides (i) data entry sheet, (ii) course information sheet (syllabus), (iii) measurement rubric and (iv) graphical charts to show results and year over year historical trends for the course. This includes a learning outcome achievement graph (see Fig. 3), that processes the data into four achievement categories Exceed, Meet, Marginal and Insufficient. The categories are fixed as determined by the Program Curriculum Committee. 


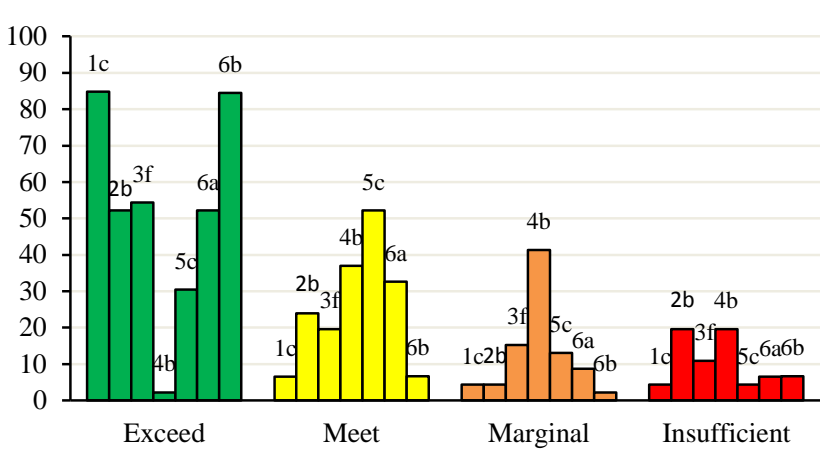

Fig.3. Student Achievement per KPI (\%).

There is also a historical trend graph type (see Fig. 4) that shows how well the course is meeting expectations for its learning outcomes over the last 4 years. The $60 \%$ boundary is the minimum score for a program to meet CAEB requirements. Data above the $80 \%$ boundary indicates a KPI for which the program has exceeded expectations. All graphs are dynamic and generated by the tool immediately after entering assessment data.

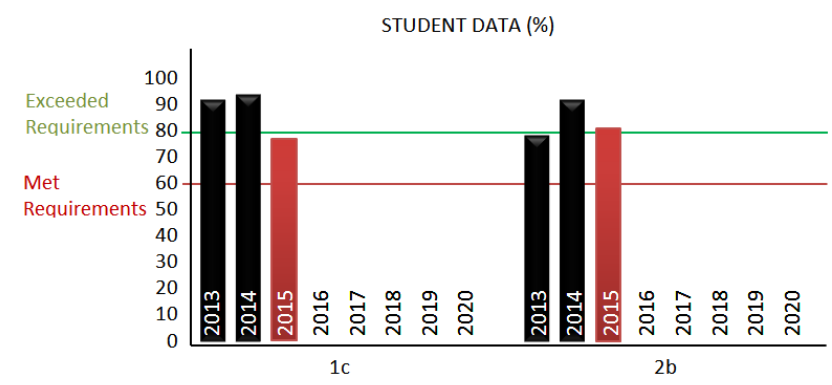

Fig. 4. Current Statistics (\%).

\section{3. Program Report Form (PRF)}

The Program Report Form (PRF) is read-only workbook. Data from all the CDEF forms for a program is imported and processed to support analysis of the program. It accommodates assessment data entered to GAIA through CEDF for all programs throughout the years. It generates reports and provides historic trends of GA data at program level.

The PRF can be accessed from the home page of each engineering program on the GAIA website. The tool measures cumulative impact data input has on program performance. It generates all types of graphs and reports needed to inform program improvement. PRF has links to Curriculum Map (CEAB 3.1.1), Attribute Indicators (CEAB 3.1.2), Assessment Tools (CEAB 3.1.3), Assessment Results Data (CEAB 3.1.4), continual improvement $\mathrm{CEAB}$ document, and a sample Course Information Sheet (Appendix 6C). It also has links to graphical presentations of each KPI assessment and shows the contribution each course has in its measurement. The tool generates reports in table form as well. They are easier to read and present information in word and number form.

\begin{tabular}{|c|c|c|c|c|c|}
\hline $\begin{array}{l}\text { GA } 5 \\
\text { (KPI 5c) }\end{array}$ & \multicolumn{5}{|c|}{$\begin{array}{l}\text { Use tools and languages for modeling, analysis and generation } \\
\text { of software structure }\end{array}$} \\
\hline \multirow{3}{*}{$\begin{array}{l}\text { Scale: } \\
55|70| 85\end{array}$} & Fall & 2013 & 2014 & 2015 & 2016 \\
\hline & Exceed & 34.5 & 35.6 & 40.7 & \\
\hline & Meet & 24.2 & 34.2 & 53.5 & \\
\hline \multirow[t]{2}{*}{ Course 1} & Marginal & 23.0 & 21.2 & 5.8 & \\
\hline & Insufficient & 9.6 & 8.9 & 0.0 & \\
\hline \multicolumn{2}{|c|}{$\begin{array}{l}\text { Requirements } \\
\text { Requirement Scale: } 60 \mid 80\end{array}$} & $\begin{array}{l}\text { Not Met } \\
58.8\end{array}$ & $\begin{array}{l}\text { Met } \\
69.9\end{array}$ & $\begin{array}{l}\text { Exceeded } \\
94.2\end{array}$ & \\
\hline \multirow{3}{*}{$\begin{array}{l}\text { Scale: } \\
55|70| 85\end{array}$} & Fall & 2013 & 2014 & 2015 & 2016 \\
\hline & Exceed & 19.1 & 17.0 & 60.0 & \\
\hline & Meet & 57.4 & 53.2 & 31.9 & \\
\hline \multirow[t]{2}{*}{ Course 2} & Marginal & 14.9 & 27.7 & 8.1 & \\
\hline & Insufficient & 8.5 & 2.1 & 0.0 & \\
\hline & Met & Met & Exceed & \\
\hline \multicolumn{2}{|c|}{ Requirement Scale: $60 \mid 80$} & 76.6 & 70.2 & 91.9 & \\
\hline
\end{tabular}

Fig. 5. Sample Table Report.

Figure 5 is a sample table report generated for the purpose of this paper. It shows one of the KPIs for GA 5 that was measured by two courses.

GAIA supports the table report by a graphical presentation of the same data. A screen shot of the graph generated from the table data above is shown on Fig. 6 below.

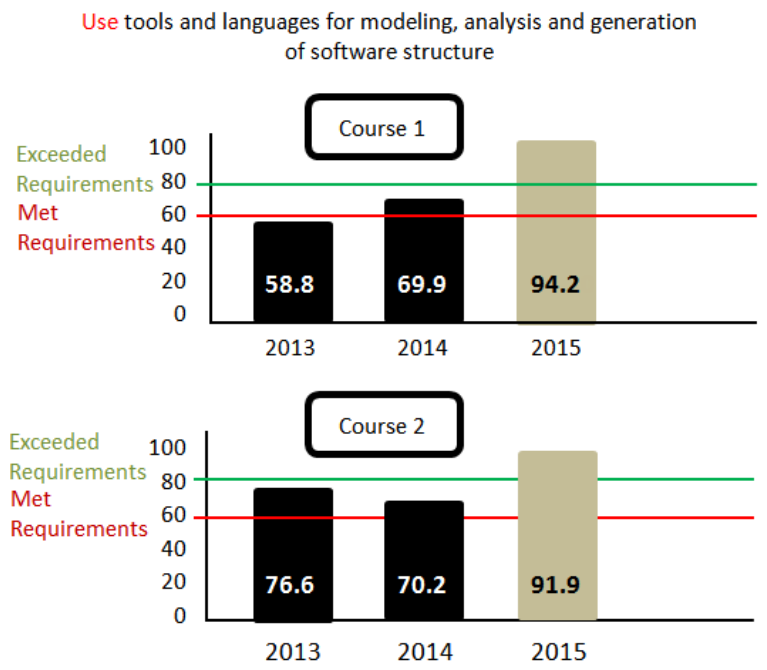

Fig. 6. Meeting Requirements Sample Graph.

\subsection{Weighted Grading}

To assure better evaluation of student achievement on a particular KPI, many instructors use combined data from several assessment tools (assignment, survey, test, lab, report). In such cases instructors had to record and average the data separately, prior to entering it into CDEF. We recently modified the data entry sheet to eliminate this time-consuming task. At its current pilot 
stage, CDEF allows recording of up to three components per KPI. It also supports weighted calculation per component. Table 1 below shows a sample of such data entry sheet. The calculation to combine the three components into a single measurement (based on the weights) is done automatically by GAIA.

Table 1: Weighted Grading Data Entry.

\begin{tabular}{|c|c|c|c|c|}
\hline & GA & \multicolumn{3}{|c|}{ GA 6} \\
\hline & KPI & \multicolumn{3}{|c|}{ KPI 6.a } \\
\hline & KPI Component & 6.a.1 & 6.a.2 & 6.a.3 \\
\hline \multicolumn{5}{|c|}{ Assessment Tool } \\
\hline \multicolumn{5}{|c|}{ Weight $(\%)$} \\
\hline \multicolumn{5}{|c|}{ Assessment Out of } \\
\hline 1 & Data Entry $_{1}$ & & & \\
\hline 2 & Data Entry $_{2}$ & & & \\
\hline.. & ........ & & & \\
\hline $\bar{i}$ & Data Entry $_{i}$ & & & \\
\hline
\end{tabular}

Instructors define the assessment tool used to measure each component and enter its weight in the overall KPI grade. The system performs automatic checking during the data entry to ensure the sum of weights assigned per component does not exceed $100 \%$. If detected, the cell becomes red, indicating the mistake. Course instructors enter maximum score ("Assessment Out of") per component and raw grades per each student ("Data Entry1, 2, ..."). The index $i$ indicates number of students. At this stage GAIA accommodates up to 1000 students.

Using the values entered the tool performs a matrix transformation to calculate the overall grade per KPI. In the explanation below we refer to:

$$
\begin{aligned}
\boldsymbol{C}_{i j}= & \text { Student Grade per Component, } \\
& 0 \leq C_{i j} \leq M S \\
& \text { where } \mathrm{i}=1 \ldots \mathrm{m} \text { (number of students), } \\
\mathrm{j}=1 \ldots \mathrm{n} \text { (number of KPI components) } & \\
\boldsymbol{W}_{j}= & \text { Weight per Component, } \\
& \text { where } \mathrm{j}=1,2,3 \\
& \text { and } \sum_{j=1}^{3} W_{j}=100
\end{aligned}
$$

The equivalent matrix form of the data entry is:

$$
\left(\begin{array}{lll}
W_{1} & W_{2} & W_{3} \\
C_{i j} & C_{i j} & C_{i j} \\
C_{i j} & C_{i j} & C_{i j} \\
\cdots & \cdots & \cdots \\
C_{i j} & C_{i j} & C_{i j}
\end{array}\right)
$$

The tool generates two separate matrices - matrix $\mathrm{C}$ from the components scores and diagonal matrix $\mathrm{W}$ from the weight values. By performing matrix multiplication, the system generates weighted matrix $\mathrm{C}$.

$C_{i j}=\left(\begin{array}{ccc}C_{i j} & C_{i j} & C_{i j} \\ \cdots & \ldots & \ldots \\ C_{i j} & C_{i j} & C_{i j}\end{array}\right)_{\substack{i=1 \ldots 1000 \\ j=1,2,3}} \quad W_{3 \times 3}=\left(\begin{array}{ccc}W_{1} & 0 & 0 \\ 0 & W_{2} & 0 \\ 0 & 0 & W_{3}\end{array}\right)$

$$
A=C \times W=\left(\begin{array}{ccc}
C_{i j} & C_{i j} & C_{i j} \\
\cdots & \cdots & \cdots \\
C_{i j} & C_{i j} & C_{i j}
\end{array}\right) \times\left(\begin{array}{ccc}
W_{1} & 0 & 0 \\
0 & W_{2} & 0 \\
0 & 0 & W_{3}
\end{array}\right)
$$$$
\therefore \quad C=\left(\begin{array}{ccc}
W_{j} C_{i j} & W_{j} C_{i j} & W_{j} C_{i j} \\
\ldots & \cdots & \cdots \\
W_{j} C_{i j} & W_{j} C_{i j} & W_{j} C_{i j}
\end{array}\right)_{\substack{i=1 \ldots 1000 \\
j=1 \ldots 3}}
$$

To calculate the resultant KPI score per student, the tool performs $\sum_{j=1}^{3} W_{j} C_{i j}$ for $\mathrm{i}=1 \ldots 1000$.

GAIA handles uniform distribution (all weight values are equal), step distribution (one of the weight values is different), and linear distribution (all weight values are different).

\section{CONCLUSIONS AND FUTURE WORK}

The use of GAIA for the purposes of accreditation brought several positive outcomes. As an administrative tool, it minimizes the time needed to record and process assessment data. Being web-based, it supports data sharing and provides easy access to GA assessment records across courses and programs. The automated generation of graphs and reports supports identifying weaknesses and areas for development.

We are working on modifications that will allow GAIA to be used across all engineering programs. In the latest version of its Guide for Outcomes-based Criteria, $\mathrm{CEAB}$ has imposed two changes. One is related to a new content-level course codes. There will be three codes only - Introduced (I), Developed (D) and Applied (A). All combinations have been eliminated. This will require general revision and modification of course information sheets and graduate attributes measured by course. The second change is related to adding four explicit components to GA 1 (Knowledge base) that require comment: mathematics, natural sciences, engineering fundamentals, and specialized engineering knowledge [18]. Both changes in the requirements have not been reflected on GAIA yet. 


\section{Acknowledgements}

The work was supported by both the Faculty of Engineering at the University of Ottawa and NSERC.

\section{References}

[1] Canadian Engineering Accreditation Board, Accreditation Criteria and Procedures, Engineers Canada, Ottawa, ON, 2014, 118 pp. \{ISSN 1708-8054\}.

Available as of Apr. 19, 2016 from http://www.engineerscanada.ca/sites/default/files/2014_accr editation_criteria_and_procedures_v06.pdf

[2] J. Harris, D. Russell, and A. Steele, "Progress on Defining the CEAB Graduate Attributes at Carleton University," in Proc.CEEA Canadian Engineering Education Conf., CEEC11, (St. John's, NL; 6-8 June 2011), 5 pp., 2011.

[3] E. Csorba, D. Chelen, N. Yousefi, N. Andrews, and C. More, Graduate Attributes at the University of Alberta, a report of the Committee on the Learning Environment (CLE) Subcommittee on Attributes and Competencies. Submitted to the June 5, 2013 CLE meeting, 2013, 22 pp.

Available as of Apr. 19, 2016 from http://www.provost.ualberta.ca/en/ /media/provost/Docume nts/Information/GraduateAttributes.pdf

[4] P. Ostafichuk, "A Shift to Outcomes-Based Assessment in Engineering." Mechanical Engineering, UBC, 12 pp. Available as of Apr. 19, 2016 from http://ctlt.ubc.ca/files/2012/01/engplga.pdf

[5] Faculty of Science, University of Calgary, Graduate Attributes Framework, Calgary, AB, 2016, 1 pp. Available as of Apr. 19, 2016 from http://www.ucalgary.ca/science/teaching_learning/graduate_ attributes_framework

[6] J. Kaupp, B. Frank, R. Brennan, S. Mccahan, L. Narayanan, P. Ostafichuck, N. Sepehri, and K. C. Watts, "A Comparison of Institutional Approaches to CEAB Graduate Attribute Requirements," in Proc.CEEA Canadian Engineering Education Conf., CEEC12, (Winnipeg, MB; 17-20 June 2012), 7 pp., 2012.

[7] J. Kaupp, B. Frank, and C. Watts, "Evaluation of software tools supporting outcomes-based continuous program improvement processes," in Proc. CEEA Canadian Engineering Education Conf., CEEC13, (Montréal, QC, 1720 June 2013), 8 pp., 2013.

[8] J. Kaupp and B. Frank, "Evaluation of Software Tools Supporting Outcomes-Based Continuous Program Improvement Process. Part 2", in Proc. CEEA Canadian Engineering Education Conf., CEEC14, (Calgary, AB, 8-11 June 2014), 10 pp., 2014.

[9] J. Kaupp and B. Frank, "Evaluation of software tools supporting outcomes-based continuous program improvement processes. Part 3," in Proc. CEEA Canadian
Engineering Education Conf., CEEC15, (Hamilton, ON, May 31-June 3, 2015), 8 pp., 2015.

[10]A. L. Saunders and L. B. Mydlarski, "Evolution of graduate attribute assessment and continuous program improvement in the Faculty of Engineering at McGill University", in Proc. CEEA Canadian Engineering Education Conf., CEEC15, (Hamilton, ON, May 31-June 3, 2015), 6 pp., 2015.

[11]Eugene O. Essa, "ACAT: ABET Course Assessment Tool," University of Nevada, Reno, 2010, 73 pp.

Available as of Apr. 19, 2016 from

http://csi.fau.edu/wp-

content/uploads/2013/03/Essa_ACAT_MS-Thesis_U-of-

Nevada_Reno_2010.pdf

[12]A. Radloff, B. De La Harpe, H. Dalton, J. Thomas, A. Lawson, "Assessing Graduate Attributes: Engaging Academic Staff and their students," in ATN Assessment Conference 2008 (Adelaide, Australia, 20-21 Nov., 2008), 7 pp., 2008.

[13]K. Chanock, "Developing criteria to assess graduate attributes in students' work for their disciplines," Journal of Learning Development in Higher Education, no. 6, p. 16, 2013. \{ ISSN: 1759-667X\}

Available as of Apr. 19, 2016 from http://www.aldinhe.ac.uk/ojs/index.php?journal=jldhe\&page $=$ article\&op=view\&path[]=197\&path[]=153

[14]A. Jones, "Generic attributes as espoused theory: The importance of context," Higher Education., vol. 58, issue 2, pp. 175-191, 2009. \{DOI 10.1007/s10734-008-9189-2\}. Available as of Apr. 19, 2016 from http://link.springer.com/article/10.1007\%2Fs10734-0089189-2\#page-2

[15]G. Mccabe, "Graduate Attributes and Employability: helping universities and students prepare for the changing landscape," Centre for Teaching,Learning and Assessment, University of Edinburgh, 3 pp., 2010.

Available as of Apr. 19, 2016 from http://www.employability.ed.ac.uk/documents/Staff/Intercha nge-GA-March2010.pdf

[16]P. Hager and S. Holland (eds), Graduate Attributes, Learning and Employability. Springer, 3300 AA Dordecht, The Netherlands, 2006, 307 pp. \{ISBN 978-1-4020-5342-9\}.

[17]S. C. Barrie, "Understanding What We Mean By Graduate Attributes," Higher Education., vol. 51, issue 2, pp. 215241, March 2006. \{DOI 10.1007/s10734-004-6384-7\}. Available as of Apr. 19, 2016 from http://link.springer.com/article/10.1007\%2Fs10734-0046384-7\#/page-1

[18]Canadian Engineering Accreditation Board, A Guide to Outcomes-based Criteria, CEAB, Canada, Ottawa, ON, March 2015 (version 1.25), 35 pp.

Available as of Apr. 19, 2016 from https://www.engineerscanada.ca/sites/default/files/draft_pro gram_visitor_guide_v1.25.pdf 